\title{
Segurança alimentar russa: estratégia de autonomia para uma estrutura internacional de incertezas
}

\author{
Russian food security: an autonomy strategy \\ for an uncertain international structure
}

Rev. Bras. Est. Def. v. 5, n 1, jan./jun. 2018, p. 273-294

DOI: 10.26792/RBED.v5n1.2018.75064

ISSN 2358-3932

THIAGO LIMA

ATOS DIAS

\section{INTRODUÇÃO}

A insegurança alimentar de uma nação é geralmente associada à debilidade do Estado e à instabilidade social (Patel e McMichael 2009). Não é de se estranhar, portanto, que os governos que busquem estabilidade, segurança e desenvolvimento deem alto grau de importância a essa questão. A Rússia contemporânea não parece fugir a esta tendência. Desde o início do século XXI, a preocupação do país com relação à segurança alimentar interna tem crescido significativamente.

A literatura aponta que três fatores principais (apresentados aqui sem ordem de importância) podem ter alavancado o cuidado do governo russo com relação ao tema. O primeiro foram as crises dos anos 2000 , sobretudo a alimentar. Atenta à vulnerabilidade do país frente ao mercado internacional de alimentos, Moscou passou a intensificar políticas de proteção e desenvolvimento da produção agrícola interna no intuito de reduzir a necessidade de se importar alimentos.

$\mathrm{O}$ segundo e o terceiro fatores se referem ao tenso contexto geopolítico russo, marcado inclusive por disputas territoriais militarizadas em casos como os da Ossétia do Sul, Geórgia, Ucrânia e Crimeia, bem como pela hostilidade do Ocidente, liderado pelos EUA. As sanções impostas por grandes potências ocidentais contra a Rússia, em 2014, por causa das investidas do país na Crimeia e em regiões separatistas da Ucrânia, parecem ter sido relevantes para a cristalização da percepção de estado de cerco a

Thiago Lima - Doutor em Ciência Política pela Universidade Estadual de Campinas (Unicamp).

Atos Dias - Mestre em Gestão Pública e Cooperação Internacional pela Universidade Federal da Paraíba (UFPB). 
que o país se sente vulnerável. Como resposta, Moscou embargou a importação de uma série de alimentos oriundos de países do Ocidente. A princípio, essas proibições poderiam ser vistas como mero exercício retaliatório. Contudo, um exame mais profundo indica que elas também respondem a dinâmicas domésticas. Neste âmbito, os fatores dois e três podem ser reconhecidos. $\mathrm{O}$ segundo entende as proibições como uma jogada política nacional para demonstrar força, reforçar a percepção de inimigos exteriores, acirrar o nacionalismo e favorecer interesses empresariais associados ao Kremlin. O terceiro compreende os bloqueios como oportunidades para aplicar um protecionismo capaz de sustentar uma política estratégica de longo-prazo de substituição de importações, com vistas a criar um forte setor agroalimentar, inclusive com perspectiva de aumentar exportações.

De imediato, é importante salientar que o projeto de segurança alimentar alavancado pelo governo russo carrega em si uma visão bastante distinta a respeito do entendimento mais conformado em nível internacional do que seja segurança alimentar e nutricional. Este está mais ligado à garantia adequada do acesso físico, econômico e social à alimentação adequada para uma vida saudável, inclusive via mercados internacionais. Acesso - e não produção ou autossuficiência - é a palavra-chave. De maneira oposta, o projeto russo almeja atender à demanda nacional por alimentos a partir da intensificação da produção interna, pois considera que depender do acesso a fornecedores estrangeiros cria uma vulnerabilidade indesejável.

A partir do exame do projeto russo de segurança alimentar - centrado na autonomia agrícola interna e na redução das importações de alimentos - o artigo argumenta que a "Doutrina Russa" é uma expressão da busca do Kremlin por redução das vulnerabilidades econômicas do país em um contexto geopolítico que lhe é inóspito, bem como de uma reinserção econômica internacional mais soberana (menos sujeita a decisões estrangeiras) e mais favorável à sua projeção de poder. ${ }^{1}$ Ao buscar esses objetivos por meio da instalação de complexos agroindustriais, a estratégia da Rússia não parece ser inovadora e sim ser uma versão algo similar das estratégias aplicadas por agropotências como União Europeia e Brasil, em que a introdução de sofisticados métodos industriais de produção agrícola geram uma quantidade de excedentes que, ao final, precisarão ser exportados.

O método de pesquisa consistiu primordialmente na revisão bibliográfica e no exame de documentos, de dados de produção e comércio. Este texto está organizado da seguinte forma: na seção "Doutrina Russa e a segurança nacional" são examinados documentos que expressam a política de segurança alimentar russa. Na seção "Poder agroalimentar: variável fundamental para as grandes potências?” exploramos a importância do fator produção agrícola/alimentar para o poder de uma nação. Analisamos, 
na seção "Segurança alimentar para além do limite da racionalidade econômica”, se a política atual de segurança alimentar russa é realmente peculiar frente às definições internacionais do termo. Nas considerações finais, apresentamos conjecturas derivadas desse movimento russo. Se confirmada a proposta russa de maior autonomia agroalimentar, o Brasil poderá enfrentar dificuldades para acessar um importante mercado de exportação.

\section{DOUTRINA RUSSA E A SEGURANÇA NACIONAL}

O péssimo desempenho econômico da Rússia nos anos 1990 e a desestruturação produtiva no processo de transição para o capitalismo chegou a tal ponto que foi preciso receber ajuda alimentar humanitária do Ocidente para evitar a catástrofe da fome. A vulnerabilidade do Estado russo estava amplamente exposta em um dos elementos mais simples e fundamentais do poder nacional: o abastecimento alimentar. Assim, no começo dos anos 2000, a coalizão de forças que assumiu o governo buscou eliminar o hiato entre a segurança alimentar e a soberania nacional (Malle 2016; Connolly e Hanson 2016). Como resultado, a Doutrina de Segurança Alimentar da Federação Russa (DR) foi publicada em 2010 e a Estratégia de Segurança Nacional da Federação Russa (ESNFR) em 31 de dezembro de 2015. Esses documentos devem ser analisados em conjunto.

A ESNFR afirma estar fundamentada em uma inseparável interconexão de dependência entre a segurança nacional russa e o desenvolvimento socioeconômico do país. (ESNFR 2015). Essa relação fica clara quando o documento argumenta que garantir segurança nacional significa proteger os indivíduos, a sociedade e o Estado das ameaças internas e externas. Essas ameaças não se referem apenas à soberania, independência e integridade territoriais. Relacionam-se, também, à garantia de qualidade de vida decente, dos direitos e liberdades constitucionais dos cidadãos e ao desenvolvimento socioeconômico sustentável. Portanto, em visão ampla, o documento considera que a segurança nacional russa abarca diversos tipos de segurança. Isto é, para além da defesa territorial resguardada no poder militar, o documento toma em consideração questões, econômicas, ambientais, energéticas e de transporte, por exemplo (ESNFR 2015).

Para garantir a segurança nacional, o documento afirma que é preciso desenvolver capacidades que permitam reforçar seu papel num mundo policêntrico em formação (idem, 2.7), inclusive diante das medidas econômicas restritivas tomadas contra a Rússia por um certo número de países, principalmente os Estados Unidos e seus aliados, que visam manter sua dominância nas questões mundiais (idem, 2.12). Na construção desse mundo policêntrico, a ESNFR reconhece a tendência de aumento da ins- 
tabilidade regional e global (idem, 2.13), bem como o papel importante da força nas relações internacionais (idem, 2.14). Neste contexto, destaca que o poder militar é fundamental para defender-se da crescente ameaça da OTAN (idem, 2.15). No que toca à segurança alimentar, o documento reconhece que o problema está se tornando mais complexo, compondo, com outros fatores socioeconômicos, a visão prospectiva de crescente instabilidade (idem, 2.23).

Neste cenário turbulento - segue o documento -, os Estados estão assumindo cada vez mais responsabilidade pelos assuntos em nível regional. De maneira específica, o comércio regional e outros acordos econômicos estão se tornando um dos mais importantes meios de proteção contra fenômenos de crise. A ESNFR aponta, por exemplo, que existe um interesse crescente na utilização de moedas regionais (idem, 2.25). Isto significa que a confiança na ideia de mercados globais e de uma ordem internacional liberal como ambiente natural para prosperar se torna demasiadamente arriscada.

Assim, para garantir a segurança nacional, o documento assegura que a Rússia está concentrando esforços no fortalecimento da unidade nacional, por meio da estabilidade social, dos acordos interétnicos e da tolerância religiosa, e, mais do que isso, eliminando desequilíbrios estruturais e modernizando a economia (idem, 2.26). Desenvolver boas relações de cooperação internacional também é importante e a opção militar, obviamente, não é descartada quando as opções não-violentas estiverem exauridas.

Reconhecemos que diversos elementos textuais são polêmicos, especialmente aqueles que tocam nas questões sociais e cívicas, e não temos pretensão de analisá-los aqui. Nosso objetivo é perscrutar a questão do abastecimento alimentar. Assim, no rol de interesses estratégicos nacionais de longo-prazo para a plena garantia da segurança nacional, a segurança alimentar (idem, 54) está contemplada nas seguintes diretivas:

- Alcançar a independência alimentar da Federação Russa;

- Acelerar o desenvolvimento e a modernização dos complexos agroindustriais e pesqueiros, da indústria alimentícia e da infraestrutura do mercado interno;

- Aumentar a eficácia do apoio estatal aos produtores agrícolas de commodities e ampliar seu acesso ao mercado para a venda de produtos;

- Desenvolver pecuária, seleção e desenvolvimento de sementes, aquicultura (criação de peixes), formar reservas federais suficientes de sementes de plantas agrícolas (incluindo estoques de reserva de sementes) e desenvolver a produção de rações mistas, e de suplementos e pré-misturas de proteínas, vitaminas e minerais e de produtos veterinários (animais); 
- Aumentar a fertilidade do solo e prevenção do esgotamento e da redução de área de terras agrícolas e pastagens

- Impedir a circulação descontrolada de organismos geneticamente modificados desenvolvidos para serem dispersos no meio ambiente e de produtos obtidos através da utilização desses organismos ou que os contenham

- Melhorar o sistema de regulamentação técnica, a higiene e a fiscalização fitossanitária, e o monitoramento no domínio da inocuidade dos produtos alimentares para a saúde humana;

- Formar cientistas e especialistas altamente qualificados no domínio da agricultura (idem, 54).

Os destaques em itálico acima já estavam de alguma maneira contemplados na DR. Elaborada primeiramente em 2008 e publicada em janeiro de 2010, ela reverbera tensões conjunturais decorrentes das crises alimentar, climática, energética e financeira de 2007/2008, bem como catalisam tendências iniciadas no começo dos anos 2000 (Vassilieva e Smith 2010; Malle 2016; Connolly e Hanson 2016; Wegren et al. 2017). O documento foi elaborado no contexto da então National Security Strategy of the Russian Federation until 2020 de maio de 2009, e tem o objetivo de contribuir para a transformação da Federação Russa em uma potência mundial num cenário de multipolaridade (apud Vassilieva e Smith 2010).

A contribuição estratégica da segurança alimentar russa é abastecer a população do país com produtos agrícolas, pesqueiros e alimentícios seguros. A estabilidade da produção nacional, bem como a disponibilidade de reservas e estoques necessários, é fundamental para o alcance da meta de segurança alimentar russa (apud Vassilieva e Smith 2010). Em curtas palavras: independência agroalimentar via modernização de complexos agroindustriais e formação de estoques. Como abordaremos adiante, tanto o incentivo a um alto grau de autossuficiência quanto a formação de estoques nacionais são políticas que desafiam os ditames da ordem econômica internacional contemporânea. No mínimo, a DR demonstra que o Kremlin não está disposto a permitir que a inserção internacional da Rússia se dê na condição de dependência da importação de alimentos. Claramente, o incômodo com a dependência das importações está associado à perspectiva de crescente tensionamento da geopolítica global e ao risco inaceitável de incorrer em desabastecimento por estrangulamento externo.

A ESNFR (2015) define independência alimentar como sendo "Produção doméstica sustentável de produtos alimentícios em quantidades não inferiores aos limiares estabelecidos como sua parcela das commodities domésticas relevantes”. Entre outras, essas medidas/referências referem-se 
aos seguintes percentuais de produção nacional do consumo de certos grupos alimentares: grãos, 95\%; açúcar, $80 \%$; óleo vegetal, $80 \%$; carne e produtos derivados $85 \%$; leite e laticínios, $90 \%$; pescado, $80 \%$; batatas, $95 \%$; sal comestível, $85 \%$. Não à toa, são esses os principais componentes da base da dieta alimentar russa.

Wegren et al (2017) afirmam que em 2015 essas metas foram revisadas para cima e a nova proposta passou a ser tornar a Rússia um fornecedor global de alimentos. De fato, já há alguns anos têm sido frequentes as reportagens sobre a ascensão meteórica da Rússia como uma agropotência exportadora (Sputnik 2018b). Assim, é importante frisar que a independência alimentar não significa fechar-se às importações e que a participação na Organização Mundial de Comércio, aliás, é vista como uma possibilidade para fortalecer a segurança alimentar. Para o Kremlin, a busca por um determinado grau de autossuficiência não é sinônimo de enclausuramento, mas sim de excesso de oferta. É nesse sentido que a ESNFR (2015, 62) estabelece como princípio fundamental "implementar a substituição racional de importações, reduzindo a dependência crítica de tecnologias estrangeiras e de produtos industriais, e acelerar o desenvolvimento do complexo agroindustrial e da indústria farmacêutica", assim como "criar reservas estratégicas de recursos minerais e de matérias-primas suficientes para garantir as necessidades de mobilização da Federação Russa e as exigências da economia do país a longo prazo”. Por fim, a Estratégia enfatiza a importância de se reavivar e cultivar a identidade nacional. A alimentação a partir de gêneros locais é, certamente, crucial para isso. Dito de outro ângulo, a incorporação de hábitos alimentares "globalizados", quando baseados em insumos e métodos que não são reproduzíveis internamente, aumenta a vulnerabilidade do país ao fornecimento estrangeiro.

\section{PODER AGROALIMENTAR: VARIÁVEL FUNDAMENTAL PARA AS GRANDES POTÊNCIAS?}

É necessário desmistificar a ideia (por vezes defendida no âmbito acadêmico) de que a produção agrícola em larga escala está majoritariamente atrelada a países em desenvolvimento ou de menor desenvolvimento relativo do sistema internacional. A ideia de que países ricos são responsáveis pela produção de bens manufaturados e de alto valor agregado, e que aos países periféricos cabe a oferta internacional de produtos primários (dentre os quais commodities agrícolas), não condiz com a realidade econômica e geopolítica internacional desde o século XX, sobretudo após a Segunda Guerra Mundial (McMichael 2013). Não é a produção de bens primários a característica responsável pelo menor desenvolvimento de países no siste- 
ma internacional, e os dados relativos ao comércio internacional demonstram isso.

Se atentarmos para os cinco grãos mais consumidos em todo o mundo, temos que: a China domina a produção de arroz e de trigo, os EUA são responsáveis pela maior parte da produção de milho e de sorgo e a Rússia lidera a produção de cevada. Se tomarmos a União Europeia como produtor único, a entidade encabeça a produção de cevada e de trigo (USDA 2017).

Mais do que isso, considerando a escala dos cinco maiores exportadores agrícolas de 2015, visualizamos que a União Europeia se coloca na liderança, e é seguida por EUA, Brasil, China e Canadá. É interessante notar também que, no mesmo ano, grandes economias estavam também presentes na lista dos maiores importadores de produtos agrícolas, como: União Europeia, China, EUA, Japão, Canadá, Índia, México e Rússia (esta última ocupando o nono lugar) (WTO 2017).

Os dados supracitados mostram, a princípio, que grandes economias figuram entre os dominantes no comércio internacional de produtos agroalimentares em termos de produção, importação e exportação. A atividade em questão ocupa, portanto, um lugar de importância nas agendas de economia e comércio internacional desses Estados.

Mas, para além desse aspecto transacional mais imediato, bem como dos efeitos multiplicadores indiretos que gravitam em torno da indústria da agroexportação, intrinsecamente ligados aos interesses de poderosas corporações (McMichael 2013; Lima 2012), a importância dada por países ricos à produção agrícola em larga escala também possui um caráter político extremamente importante (Patel e McMichael 2009; Paarlberg 2010).

Primeiramente, há de se considerar que o suprimento agroalimentar inadequado impacta o sistema político, podendo afetar a ordem pública interna. De certo modo, a greve de caminhoneiros de 2018 mostrou ao público brasileiro os riscos de uma crise de desabastecimento prolongada. Alimentar o povo é uma fonte de legitimidade para o Estado. "Toda vez que, no curso da história, a segurança alimentar foi gravemente afetada, a incapacidade de restabelecê-la foi seguida, mais cedo ou mais tarde, de sérios distúrbios sociais" (Alencar 2001, 139). Os eventos da Primavera Árabe são exemplos recentes de grande expressão. ${ }^{2}$ Bassou (2016) aponta que os países poupados pela revolta foram ou aqueles que garantiram o abastecimento alimentar interno com receitas oriundas do petróleo, ou que tinham uma política agrícola bem estabelecida. Não é preciso, no entanto, ir a tais extremos para se entender a importância de um suprimento adequado - quer dizer, abundante, de acordo com os hábitos culturais, e de preços baixos. A inflação de alimentos em si já é motivo para se questionar os políticos no poder e abrir janelas de contestação. Portanto, se parece 
improvável que um bloqueio internacional seja capaz de esfaimar a Rússia, os governantes russos precisam impedir que um descontentamento sobre esse aspecto basilar da vida - a alimentação - emerja e mine seu projeto nacionalista de reinserção internacional $\operatorname{ESNFR~(2015,~2.11).~}$

Seria exagero apontar a produção alimentar como uma ferramenta de hard power? Dentre as doze potências com maiores índices de hard power (EUA, China, Índia, Rússia, Japão, Brasil, Alemanha, França, Canadá, Reino Unido, Austrália e Itália), apenas três dessas (Japão, Reino Unido e Itália) não estão incluídas no quadro dos 11 maiores produtores agrícolas, provavelmente por limitações geográficas. ${ }^{3}$ Concordamos com Bassou $(2016,4)$ que, "se a agricultura não pode, sozinha, assegurar a inserção adequada de um Estado internacionalmente, permanece o fato de que a imagem do poder é inconsistente com a dependência em termos de segurança alimentar”. Em outros termos, isso significa dizer que, embora a agricultura não seja uma variável suficiente que ateste o poder de uma nação, ela pode ser, no entanto, um componente bastante relevante.

Essa conjunção entre atividade agrícola, política internacional e segurança nacional já era bastante clara aos olhos de Morgenthau (2003), sobretudo no que diz respeito à questão alimentar. $\mathrm{O}$ realista argumentou que os alimentos são o mais elementar dentre os recursos naturais que constituem o poder de uma nação. "Um país que seja autossuficiente, ou quase, em comida já conta com uma grande vantagem inicial sobre qualquer outro que, para não se exaurir de inanição, tenha de importar os alimentos que não produz” (idem, 220). A escassez de alimentos, portanto, representa uma fraqueza no campo da política internacional, uma vez que submete países às transações do mercado internacional, onde atores diversos atuam na tomada de decisão e os resultados dessas interações se caracterizam por um alto nível de volatilidade. Em outras palavras, a autossuficiência alimentar garante uma atuação política internacional mais ativa e "constitui um elemento relativamente estável na formação do poder nacional” (Morgenthau 2003, 222). Os países com menor desenvolvimento relativo, por exemplo, "vivem continuamente sob a ameaça da fome e da realidade da subnutrição, sem poderem contar com a maioria dos outros recursos que costumam integrar o poder nacional"; eles "se limitam a esperar que a generosidade internacional os ajude a sobreviver até a próxima crise de fome" (idem, 222).

Embora possa aparentar, essa ligação entre agricultura e o nível de poder e segurança de uma nação não é "fetiche de realista”. Keohane e Nye (2012), (institucionalistas neoliberais das Relações Internacionais) explicam que a interdependência pode configurar-se como um recurso de poder entre os atores internacionais. A interdependência na política mundial 
"refers to situations characterized by reciprocal effects among countries or among actors in different countries" (idem, 7). Isso significa dizer que as decisões tomadas por um certo país podem impactar de alguma forma os demais. Esse cenário faz com que não apenas assuntos militares sejam valorizados nas relações estratégicas entre países, e a questão agrícola/alimentar não escapa dessa lógica. Os autores em questão esclarecem esse argumento ao citar o seguinte exemplo:

Consideremos o comércio de produtos agrícolas entre os Estados Unidos e a União Soviética de 1972 a 1975. Inicialmente, a economia americana era altamente sensível às compras soviéticas de grãos: os preços dos grãos aumentaram dramaticamente nos Estados Unidos. A União Soviética também era sensível à disponibilidade de excedentes americanos, já que sua ausência poderia ter implicações políticas e econômicas internas. As assimetrias de vulnerabilidade, no entanto, correram fortemente a favor dos Estados Unidos, já que suas alternativas à venda de grãos à URSS (como o armazenamento do governo, preços domésticos mais baixos e fornecer mais ajuda alimentar no exterior) eram mais atraentes do que a alternativa soviética básica à compra de grãos dos Estados Unidos (abate de gado e redução do consumo de carne). Assim, enquanto o governo dos Estados Unidos pudesse reter o controle coerente da política - isto é, contanto que os grupos de interesse com uma participação no comércio não controlassem a política - o comércio agrícola poderia ser usado como uma ferramenta de barganha política com a União Soviética (Keohane e Nye 2012, 13).

Assim, pode-se considerar que a interdependência entre os países na questão alimentar, somada a suas assimetrias quanto à capacidade de produção agrícola, abre espaço para que uns possuam a habilidade de exercer poder sobre outros quando houverem vulnerabilidades e sensibilidades a serem exploradas (Keohane e Nye, 2012). Ter uma boa capacidade endógena de produzir alimentos é uma precaução não desprezível. Outra precaução seria diversificar fornecedores.

Não se pode exagerar, no entanto, a eficácia dos alimentos como recurso de poder nas relações entre grandes potências. Discutimos esse ponto em outro artigo (Lima 2014; Lima e Dias 2016). É certo que, em situações de guerra geral, como nas mundiais, a capacidade de suprir os aliados não é algo trivial. Por outro lado, a ajuda alimentar pode contribuir para compor o soft power na relação com pequenas potências. Sua recusa (ou embargo) poderia exercer pressão concreta, como hard power, sobre Estados débeis. Durante a Guerra Fria, por exemplo, muitos dos alimentos subvencionados pelos EUA eram usados para custear alojamento militar e equipamen- 
tos de defesa no exterior. Essas operações seriam uma forma de vincular-se indiretamente os alimentos aos instrumentos de hard power. Mesmo assim, a eficácia pode ser limitada se outros Estados resolverem suprir os alimentos negados, ou seja, é uma tática que demanda colaboração por parte dos países exportadores. Ainda no caso do embargo ao fornecimento, duas limitações domésticas são prováveis: é de se esperar que surja oposição ao próprio embargo tanto por parte do público afeito aos Direitos Humanos, que não tolera a tática de esfaimar o estrangeiro, principalmente porque sabe que as elites governantes não sofrerão com a carestia, quanto dos exportadores, que perdem mercado consumidor para concorrentes. ${ }^{4}$

De todo modo, a capacidade de suprir suas próprias necessidades parece ser o papel mais importante que a produção agroalimentar pode desempenhar na composição do poder nacional. A grave crise alimentar global de 2007/2008 demonstrou mais uma vez que confiar o abastecimento nacional ao mercado internacional não é isento de riscos, pois quando o preço dos alimentos começou a disparar, países exportadores restringiram suas próprias exportações para evitar desabastecimento ou inflação nacionais, o que agravou o problema daqueles dependentes de importações (Lima e Leite 2016; McMichael 2013). E isso porque a crise ocorreu num contexto em que não havia tensões geopolíticas ameaçando as rotas de suprimento oceânicas.

Assim, desde um ponto de vista mais realista das relações internacionais, os Estados devem buscar minimizar suas vulnerabilidades, dependendo o menos possível - conforme as possibilidades concretas de cada realidade em particular, levando-se em conta as capacidades econômicas, o contingente demográfico, as dotações geográficas, etc. - das decisões de produção e fornecimento de estrangeiros. Estáveis hoje, elas podem se tornar instáveis amanhã. Aos estadistas e elites prudentes, cabe administrar a incerteza e precaver o Estado. Recorde-se que esse foi o caminho seguido pela enfraquecida Europa Ocidental (hoje União Europeia) no processo de independência de seus impérios ultramarinos: ao perder o controle formal sobre as decisões de produção e comercialização daqueles territórios, bem como a capacidade de defender autonomamente a marinha mercante nos oceanos, os europeus, fustigados pela fome durante as Guerras, constituíram uma Política Agrícola Comum que mudou o perfil daquela região do globo, tornando-a relativamente autossuficiente na produção de alimentos básicos e com excesso de oferta para alguns gêneros elementares como trigo e laticínios. Esta transição, efetuada para acomodar as potências daquela região à sua nova posição na hierarquia geopolítica, ocorreu seguindo o modelo estadunidense dos Complexos Agroindustriais e contou com apoio do Plano Marshall (Veiga 2007; McMichael 2013). 
Muitos Estados, no entanto, não possuem capacidade de aumentar sua produção doméstica e buscam diminuir os riscos do abastecimento via fornecimento estrangeiro por meio de diversas estratégias internacionais, que vão desde a compra no mercado de futuros, passando pela cooperação técnica que visa ampliar as áreas de cultivo no exterior, até a compra de fazendas com a finalidade de exportar diretamente para o mercado-mãe (Moyo et al. 2012; McMichael 2013). Esse é um tema complexo e não temos condições de abordá-lo aqui. Basta indicar que países como Japão, Coreia do Sul, China e Arábia Saudita, entre outros, fazem parte desse processo chamado por alguns de "estrangeirização de terras" (Lima e Leite 2016). Embora essa estratégia possa de fato aumentar a diversidade de fornecedores, não se pode esquecer - mais uma vez - os embargos impostos à exportação de grãos justamente em meio à crise de 2007/2008. A própria Rússia embargou suas exportações de trigo em 2008 e 2010 !

Bem-dotada territorialmente e com vastas áreas ociosas, a Rússia tem sido apontada como um alvo/receptora de investimentos estrangeiros no processo global de land grabbing. Contudo, nem o governo nem a maioria da população parecem se opor a esse movimento. Do ponto de vista do Estado, o investimento estrangeiro parece compor com a estratégia de ampliação nacional da produção. Não é estranho, portanto, que a Rússia tenha interesse em alavancar a sua produção agrícola para se defender das vulnerabilidades decorrentes do fornecimento via mercado internacional num contexto geopolítico que lhe é crescentemente tenso. Ademais, a perspectiva de aumento da demanda chinesa, ainda mais no contexto de estreitamento da parceria estratégica entre ambos, configura importante incentivo para o desenvolvimento de capacidade agroexportadora.

Como coloca Bassou (2016), esse tipo de estratégia russa internaliza o princípio de que a dependência impede o desfrute do poder. Uma lembrança dos anos 1990 ilustra o ponto para a Rússia: devido a uma grave quebra de safra em 1998 - a pior desde os anos 1950 -, EUA e União Europeia forneceram ajuda alimentar aos russos até 2000 para impedir uma séria crise de fome. Na gestão do desabastecimento, o governo impediu que determinadas regiões vendessem alimentos para outras dentro do país, bem como aplicou embargos às exportações. Além da quebra episódica de safra, a pobreza e a queda na produção agrícola, como resultado da transição para o modelo capitalista, agravaram a situação (Wegren et al. 2017). Em outras palavras, a população e o Estado careciam de renda e de estoques num momento de produção nacional insuficiente, colocando a líder URSS de outrora na condição de receptora de ajuda alimentar do Ocidente.

Putin assumiu o poder em 2000 e, desde então, fortalecer a produção agrícola se tornou um imperativo (Wegren et al. 2017). Em seu concei- 
to de "soberania econômica", o setor agroalimentar foi considerado uma prioridade em termos de segurança nacional, juntamente com a segurança energética, informacional e militar (ESNFR, 2015). ${ }^{5}$

Como a Doutrina tem sido implementada na prática? Qual o grau de seriedade que é possível conferir a ela? Malle (2016) e Connolly e Hanson (2016) discutiram as dificuldades estruturais de se aplicar a doutrina de substituição de importações, especialmente num cenário de dificuldades econômicas, mas são unânimes em afirmar que se trata de um projeto sério e prioritário. Na mesma direção, Wegren et al (2017, 7) apontam que, para atingir os objetivos da segurança alimentar, o orçamento federal mais do que duplicou de 2010 a 2015, saltando de 120 para 237 bilhões em rublos nominais. Para 2018, a expectativa é que sejam liberados 272 bilhões de rublos, o que corresponde a 15 bilhões de reais. Recursos públicos têm subsidiado a compra de gado de corte e vacas leiteiras de pedigree. Há também subsídios diretos à produção de leite, além do apoio do mais alto nível para a pecuária em geral, inclusive com o objetivo de desenvolvimento de capacidade exportadora. Há subsídios para a compra de máquinas agrícolas, sementes de alta qualidade, fertilizante mineral, pesticidas, assim como para o transporte de grãos via ferrovia. Serviços financeiros como seguro de safras e empréstimos de curto (um ano) e longo prazo (oito anos) têm sido subvencionados para incentivar melhorias de capital e aquisições de novos equipamentos ou gado. "Em suma, as declarações políticas sobre a obtenção da segurança alimentar não são meramente retórica política. Os líderes russos estão dedicando recursos significativos para o seu objetivo”, concluem Wegren et al $(2017,7)$.

Alguns impactos dessa estratégia já são quantificáveis, segundo dados do Ministério da Agricultura da Rússia (Sputnik 2018b; 2018a). A importação de alimentos caiu de $35 \%$ para menos $20 \%$ do total consumido pelo país entre 2013 e 2017. Nos últimos três anos, as importações de açúcar, carne e queijo foram reduzidas em $73 \%, 36 \%$ e $29 \%$, respectivamente, enquanto a produção nacional adquiriu capacidade de suplantar a importação de frangos e suínos. As exportações de legumes e azeite subiram $40 \%$ e a de pescado bateu o recorde histórico. No que se refere aos grãos, importante base da alimentação mundial, a Rússia detém hoje $22 \%$ das exportações mundiais de trigo, a frente da União Europeia e dos EUA, com 14\% e 13\%, respectivamente. A atual liderança russa no mercado de trigo decorre de uma série de fatores dinâmicos, como dificuldades climáticas para produção em fornecedores tradicionais, efeitos positivos do aquecimento global no território russo, mas também da abertura de novos mercados. Inclui-se, entre eles, o brasileiro, que estava fechado há 9 anos por desavenças fitossanitárias (Nenakhova 2018). As exportações de outros grãos, com a cevada, também 
têm crescido. Em suma, para Yevgeny Akhpashev, diretor do Departamento Industrial de Alimentos e Processamento, "A política de substituição das importações provou que vale em uma série de setores. Falando sobre a produção agrícola, podemos dizer que somos autossuficientes. Esperamos que o crescimento das exportações dobre até 2025" (Sputnik 2018a). Entre os fatores que contribuíram para o aumento da produção e das exportações estão as sanções e as retaliações trocadas entre o país e o Ocidente, que acabaram abrindo espaço no mercado doméstico e incentivando o setor agroindustrial russo a adquirir capacidade de exportação.

$\mathrm{O}$ imenso território russo parece ter em andamento um projeto de transformar-se em uma plataforma capaz de gerar receita a partir das exportações de alimentos. Isso pode gerar pelo menos dois tipos de benefícios indiretos. Primeiro, configura uma espécie de seguro nacional para os momentos de queda no preço do petróleo, quando diminui a capacidade de custear importações. Segundo, por que o país se torna capaz de mobilizar o excedente de alimentos como ferramenta diplomática. A Rússia pode, por exemplo, oferecer ajuda alimentar (na forma de doação ou de vendas subsidiadas) a aliados, papel este que tem sido dominado pelo Ocidente, principalmente pelos Estados Unidos, no período pós-Guerra Fria (Clapp 2012). Isto é, além de ajuda humanitária, o país pode também oferecer transações comerciais alimentares mais vantajosas a seus aliados, como no caso do acordo fechado com a Venezuela, no qual a Rússia pretende suprir todo o trigo que antes era comprado do Canadá e dos Estados Unidos. A crise alimentar na Venezuela é sabidamente um dos principais elementos desestabilizadores do país e que contribui para o enfraquecimento da legitimidade do governo de Maduro. Não à toa, a mídia estatal venezuelana divulgou o acordo como sendo uma ajuda russa no contexto da "guerra econômica" que tem sido imposta pelos opositores do governo (Reuters 2018; Telesur 2017).

\section{SEGURANÇA ALIMENTAR PARA ALÉM DO LIMITE DA RACIONALIDADE ECONÔMICA}

O conceito sobre segurança alimentar dificilmente é consensual. A Organização das Nações Unidas para Agricultura e Alimentação (FAO, na sigla em inglês) reconheceu isso ao afirmar que "a segurança alimentar é um conceito flexível, conforme se observa nas muitas tentativas de definição para fins da pesquisa ou de políticas públicas. Até uma década atrás, havia cerca de 200 definições em escritos publicados”. Por isso, continua a FAO, "sempre que o conceito é introduzido no título de um estudo ou de seus objetivos, é necessário olhar atentamente para identificar a definição explícita ou implícita” (FAO 2003, 25). 
A definição mais recente comumente aceita refere-se àquela negociada durante a Cúpula Mundial sobre Alimentação em 1996, e carrega a preocupação com a garantia do acesso aos alimentos. A definição declara que "A segurança alimentar, nos níveis individual, doméstico, nacional, regional e global, é alcançada quando todas as pessoas têm, de forma ininterrupta, acesso físico, social e econômico a alimentos suficientes, seguros e nutritivos, que atendem às suas necessidades e preferências alimentares para uma vida ativa e saudável”. (FAO 1996).

Por outro lado, a insegurança alimentar ocorre quando os indivíduos não possuem adequado acesso físico, social ou econômico à alimentação (FAO 2003). Ao se enfatizar a questão do acesso - e não a produção, por exemplo -, o conceito proposto está indicando como diretriz aos países que suas políticas públicas alimentares tenham como alicerce o fornecimento via mercados (Maluf 2007; Paarlberg 2010). Em outros termos, a ideia é a seguinte: no mundo há alimentos suficientes para todos. Se os indivíduos tiverem renda e os mercados estiverem abertos, o problema estará solucionado. Com um mercado aberto, a fome é questão de renda, e não de alimento.

É tomando essas definições mais comumente aceitas pela comunidade internacional que Wegren et al. (2017) afirmam não haver ameaça ao nível de segurança alimentar da Rússia, uma vez que a população possui, em geral, renda per capita suficiente para complementar sua demanda alimentar via mercado internacional. Ao mesmo tempo, o mercado internacional contaria com oferta suficiente para atender à demanda russa. Por isso, a agenda de segurança alimentar seria, na verdade, usada majoritariamente pelo governo para fins de política doméstica e de favorecimento de grupos econômicos aliados. Em outras palavras, as políticas adotadas pelo governo russo não refletiriam seu real nível de insegurança alimentar e seriam manipuladas com o objetivo de promover interesses estatais de natureza política e favorecimentos empresariais.

Embora o conceito supracitado seja o mais divulgado e aceito internacionalmente, inclusive por divulgação da FAO (ressonando interesses dos países agroexportadores e das grandes corporações do agronegócio), há um forte movimento internacional que o questiona e defende, alternativamente, a ideia de soberania alimentar. Este conceito enfatiza a legitimidade e o dever de se recorrer aos instrumentos do Estado para aplicar uma política de produção e abastecimento a partir do que a sociedade considerar seu ideal de alimentação - e isso normalmente inclui favorecer a produção doméstica, de gêneros nativos e locais, enfatizando os pequenos produtores e os métodos ecologicamente corretos; a administração de preços e a regulação da oferta, inclusive a proveniente do exterior. Esta é 
uma noção que "vem sendo trabalhada e difundida principalmente pelos movimentos sociais" como resposta "à perda de capacidade de os Estados nacionais formularem política agrícolas e alimentares no contexto de progressiva internacionalização da economia” (Maluf 2007, 22; McKeon 2015). De acordo com o que foi apresentado a partir do Fórum Mundial sobre Soberania Alimentar (realizado no ano de 2001 em Cuba), os povos nacionais teriam o direito de definir suas políticas e estratégias produtivas - baseando-se na pequena e média produção sustentável e respeitando seus aspectos culturais - com vistas a garantir o acesso aos alimentos por parte da população $($ idem $)$.

Podemos dizer, com isso, que o conceito de soberania alimentar surge como uma resposta política à predominância da importância do mercado como via solucionadora dos problemas de falta de acesso a alimentos por parte da população mundial. Embora o comércio internacional, atualmente bastante marcado pela agilidade dos transportes e da informação, possa garantir a satisfação alimentar das populações demandantes, muitas vezes esse acesso pode ser prejudicado devido às volatilidades deste comércio. A crise alimentar dos anos 2000 exemplifica bem como o mercado internacional está vulnerável a falhas em garantir o abastecimento alimentar internacional. O que queremos aqui demonstrar é que o conceito de segurança alimentar é um conceito historicamente usado como ferramenta política para atender a interesses políticos e econômicos (McMichael 2013).

A Doutrina Russa não se enquadra nem na definição da FAO de segurança alimentar, nem na de soberania alimentar dos movimentos sociais. $\mathrm{O}$ que se observa no caso da Rússia é a opção de reduzir sua vulnerabilidade por meio de uma reestruturação econômica calcada na implementação de Complexos Agroindustriais via processo de substituição de importações (Zeilanov e Terentev 2015; Malle 2016). É uma estratégia que se vale profundamente da capacidade indutora do Estado (e que possui semelhanças com a aplicada pelo Brasil pelos governos militares), visando a larga escala e o ganho de capacidade de exportação. Trata-se de garantir o mínimo produzindo em excesso. Ademais, as orientações neoliberais preconizam, desde os anos 1980, a privatização de estoques públicos de alimentos como forma de reduzir custos no orçamento. Os pacotes de ajuste estrutural do FMI tiveram papel relevante na desarticulação dos estoques públicos de alimentos em países em desenvolvimento endividados desde os anos 1990. O resultado dessa política foi o aumento da vulnerabilidade desses países aos choques domésticos e internacionais de oferta e de preço (Clapp 2012). A Doutrina Russa, ao buscar criar estoques de alimentos e sementes, vai na contramão da atual ordem econômica internacional. A opção por este caminho demonstra o objetivo de reduzir vulnerabilidades decorrentes do 
fornecimento estrangeiro de alimentos, opção esta que se torna mais racional conforme aumentam as tensões geopolíticas com o Ocidente.

\section{CONSIDERAÇÕES FINAIS}

Argumentamos em outro artigo (Lima 2012) que uma estratégia dos países desenvolvidos (e não desenvolvidos, como o Brasil) para garantir sua segurança alimentar é desenvolver complexos agroindustriais que produzem em excesso e que, por isso, são dependentes da intervenção estatal (principalmente na forma de subsídios) e das exportações. O caso em tela sugere que a Rússia busca seguir o mesmo caminho para adquirir ganho em escala e consolidar-se como grande agropotência. Malle (2016, 117) corrobora com essa conclusão, ao afirmar que "os altos subsídios agrícolas mantidos pelos EUA e pela UE durante décadas, apesar das recomendações da OMC, também fornecem segurança alimentar. Após décadas de dependência alimentar, a Rússia parece estar se alinhando com a prática das potências mundiais". Vejamos, à guisa de considerações finais, algumas vantagens aparentes desse modelo.

Aumentar a produtividade e a escala domésticas, de modo a poder acompanhar a acirrada competição internacional, é uma maneira razoavelmente eficiente de se manter seguro quanto ao abastecimento físico agroalimentar. A grande oferta permite evitar pressões populares e da indústria de transformação por comida/insumos mais baratos em um contexto de mercado global de commodities, e de um sistema multilateral de comércio que pressiona pela diminuição das barreiras comerciais.

A instalação de complexos agroindustriais competitivos demanda investimentos em insumos sofisticados de engenharia, química, biotecnologia, etc. Assim, a meta de aumentar produção agroalimentar por esta via traz, intrinsecamente, a oportunidade do desenvolvimento (ou ao menos a instalação de fábricas e laboratórios, inclusive via investimento estrangeiro direto) de equipamentos e insumos de alta tecnologia. Ao privilegiar a indústria e os laboratórios nacionais, a Doutrina Russa pode ganhar o apoio político desses grupos de interesse. Adicionalmente, cabe lembrar que em caso de necessidade os parques produtivos agroindustriais podem ser úteis para a produção bélica.

É provável que, se bem-sucedido, o impulso capitalista dos complexos agroindustriais gere excedentes exportáveis. Essas exportações podem contribuir para a receita nacional e para arrecadar dólares. A proximidade com os mercados importadores dinâmicos da Ásia, sobretudo Índia e China, pode se tornar uma vantagem competitiva desde que a logística seja bem desenvolvida. A perspectiva de exportação, portanto, pode im- 
pulsionar também o investimento em infraestrutura em direção ao leste. Isso contribuiria para o esforço de diminuir a dependência das relações econômicas com a Europa.

Ademais, as receitas das agroexportações poderiam contribuir para aliviar o problema cambial russo. Como a economia russa é muito dependente das exportações de petróleo, o rublo tende a flutuar conforme essas receitas. Quando o preço do petróleo aumenta, a moeda se aprecia; quando cai, se deprecia. O problema da depreciação do rublo, para a questão alimentar, é que ele impacta a inflação de alimentos. No entanto, se o país aumentar sua capacidade agroexportadora, ele tenderá a exportar ainda mais em momentos de depreciação cambial, o que poderá exercer uma contratendência com algum impacto sobre o equilíbrio do câmbio.

O problema surge quando o câmbio está apreciado - e isso nos leva a elencar, especulativamente, algumas desvantagens do modelo. É que as importações se barateiam e as commodities russas encarecem. Se a qualidade não for competitiva, a tendência é de superoferta doméstica, derrubando preços e infundindo prejuízos em cadeia para os complexos agroindustriais. A solução adotada pelos países desenvolvidos nesse caso é a prática de subsídios de exportação e, em menor medida, a doação humanitária de alimentos (que, se bem manuseada, pode aumentar o soft power). Os subsídios tendem a pesar no orçamento e receber ataques políticos tendo, por isso, efeitos colaterais negativos.

A produção de commodities de exportação é dominada pelo oligopólio de grandes corporações privadas e cabe indagar se a estratégia russa seria capaz de criar suas próprias corporações, ou se seus complexos agroindustriais seriam inseridos nas estratégias globais dessas multinacionais, abrindo flancos para sua influência econômico-política que podem contrariar os preceitos da segurança alimentar russa.

Os complexos agroindustriais normalmente não prezam pela sustentabilidade, o que contrariaria a própria $\operatorname{ESNFR~}(2015,63)$. São ancorados na larga produção de monoculturas intensivas em insumos químicos. Isso traz consequências negativas para o meio ambiente que vão desde a poluição até a eliminação da diversidade biológica. Eles também tendem a eliminar empregos rurais, concentrar terras e gerar deslocamento de populações.

Enfim, em que medida uma instalação exitosa de modernos complexos agroindustriais na Rússia permitirá uma reinserção internacional em termos que lhe são preferíveis é uma questão em aberto. A Doutrina Russa parte da leitura de que a tendência de instabilidade geopolítica pode agravar-se, modificando os parâmetros das relações econômicas internacionais e, particularmente, do modelo majoritariamente vigente de segurança alimentar (conforme definição da FAO, 1996). Na perspectiva do Brasil, é 
mister estar atento a esses movimentos, pois a Rússia é importante destino de exportações e, eventualmente, pode vir a se tornar mais um competidor internacional.

\section{REFERÊNCIAS}

Alencar, Álvaro Gurgel de. 2001. Do conceito estratégico de segurança alimentar ao plano de ação da FAO para combater a fome. Revista Brasileira de Política Internacional. Brasília, 44 (1), 137-144, jan/jun.

Bassou, Abdelhak. 2016. The importance of agricultural policy in terms of security, defense and sovereignty. OCP Policy Center. Policy Brief, Rabat, maio.

Clapp, Jenifer. 2012. Hunger in the Balance: the new politics of international food aid. London: Cornell University Press.

Connolly, Richard e Philip Hanson. 2016. Import Substitution and Economic Sovereignty in Russia. Research paper - Chatham House. Russia and Eurasia Programme. The Royal Institute of International Affairs, Chatham House, jun.

ESNFR (Estratégia de Segurança Nacional da Federação Russa). 2015. The Russian Federation's National Security Strategy, 31 dez. Disponível em: <http://www.ieee. es/Galerias/fichero/OtrasPublicaciones/Internacional/2016/Russian-NationalSecurity-Strategy-31Dec2015.pdf>. Acesso em: 20 abr. 2017.

FAO (Food and Agriculture Organization of the United Nations). 1996. Rome Declaration on World Food Security. Roma, 13-17 nov. Disponível em: <http:// www.fao.org/docrep/003/w3613e/w3613e00.htm>. Acesso em: 23 abr. 2017.

FAO (Food and Agriculture Organization of the United Nations). 2003. Trade Reforms and Food Security: conceptualizing the linkages. Roma. Disponível em: <http://www.fao.org/3/a-y4671e.pdf>. Acesso em: 23 abr. 2017.

Keohane, Robert O. e Joseph S. Nye. 2012. Power and Interdependence. Nova York: Longman. 368p.

Lima, Thiago. 2012. Agricultural protectionism in developed countries as a State interest. Brazilian Journal of International Relations, 1 (2): 60-84.

Lima, Thiago. 2014. Alimentos: um recurso de poder nas Relações Internacionais? Um exame a partir da experiência histórica dos EUA. Caderno CEDEC, 118: 1-24.

Lima, Thiago e Atos Dias. 2016. A ajuda alimentar internacional dos EUA: política externa, interesses econômicos e assistência humanitária. Revista Brasileira de Políticas Públicas e Internacionais. João Pessoa, 1 (1): 189-211. 
Lima, Thiago; Alexandre C. C. Leite. 2016. Estrangeirização de terras: um questionamento à cooperação na ordem econômica internacional contemporânea? Monções, 5 (9): 121-151.

Malle, Silvana. 2016. Economic Sovereingty: an agenda for Militant Russia. Russian Journal of Economics, Amsterdam, 2: 111-128.

Maluf, Renato. S. J. 2007. Segurança alimentar e nutricional. Petrópolis: Vozes. 174p.

Mckeon, Norah. 2015. Food Security Governance: Empowering communities, regulating corporations. Londres: Routledge.

McMichael, Philip. 2013. Food regimes and agrarian questions. Halifax e Winnigpeg: Fernwood Publishing. 196p.

Moyo, Sam, Paris Yeros e Praveen Jha. 2012. Imperialism and primitive accumulation: notes on the new scramble for Africa. Agrarian South: Journal of Political Economy, 1 (2): 181-203.

Morgenthau, Hans J. 2003. A Política entre a Nações: a luta pelo poder e pela paz. Brasília: Editora Universidade de Brasília. 1.093p.

Nenakhova, Ekaterina. 2018. Brasil abre mercado para trigo russo, pondo fim à "luta" requisitória de 9 anos. Sputnik. 26 de abril. Disponível em: $<$ https://sptnkne. ws/hvEb>. Acesso em: 28 set. 2018.

Paarlberg, Robert. 2010. Food Politics. What everyone needs to know. Oxford University Press. 280p.

Patel, Raj e Philip McMichael. 2009. A political economy of the food riot. Review: a journal of the Fernand Braudel Center, 31 (1): 9-35.

Reuters. 2018. Russian state trader to supply 300,000 T of wheat to Venezuela in 2017/18. 27 de junho. Disponível em: <https://www.reuters.com/article/ russia-venezuela-wheat/russian-state-trader-to-supply-300000-t-of-wheat-tovenezuela-in-2017-18-idUSL8N1JO4OP>. Acesso em: 29 set. 2018.

Sputnik. 2018 a Exportações de alimentos da Rússia podem duplicar até 2025 graças a sanções internacionais. 12 de março. Disponível em: <https://sptnkne. ws/gWHk>. Acesso em: 28 set. 2018.

Sputnik. 2018b. "Exportações russas de cereais estão crescendo a níveis recorde. A Sputnik explica como a Rússia está se tornando o maior fornecedor de alimentos". 30 de abril. Disponível em: <https://sptnkne.ws/hxdh>. Acesso em: 28 set. 2018. 
Telesur. 2017. Russia Helps Venezuela Fight Opposition's “Economic War”. 5 de junho. Disponível em: <https://www.telesurtv.net/english/news/Russia-HelpsVenezuela-Fight-Food-Blackmail-by-Imperialist-States-20170605-0023.html>. Acesso em: 29 set. 2018.

USDA (United States Department of Agriculture). 2017. Production, Supply and Distribution Online (PSD Online), Washington. Disponível em: <https://apps.fas. usda.gov/psdonline/app/index.html\#/app/home>. Acesso em: 17 abr. 2017.

Vassilieva, Yelena e Mary Ellen Smith. 2010. Food Security Doctrine adopted. GAIN Report Number: RS1008. USDA, Foreign Agricultural Service. 02 nov.

Veiga, José Eli da. 2007. O desenvolvimento agrícola: Uma visão histórica. São Paulo: Edusp. 234p.

Wegren, Stephen K., Alexander M. Nikulin e Irina Trotsuk. 2017. The Russian Variant of Food Security. Problems of Post-Communism. 64 (1): 47-62.

WTO (World Trade Organization). 2017. Documents, data and resources, Genebra. Disponível em: <https://www.wto.org/english/res_e/res_e.htm>. Acesso em: 17 abr. 2017.

Zeilanov, Isa e Aleksei Terentev. 2015. Principals of food security in modern Russia: political-economic aspect of the strategy. European Political and Law Discourse. 2 (2): 221-224.

Ziegler, Jean. 2013. Destruição em massa: geopolítica da fome. São Paulo: Cortez. $336 \mathrm{p}$. 


\section{NOTAS}

1. Malle (2016) aborda como a ideia de "soberania econômica", pronunciada por Putin pela primeira vez em 2015, pode traduzir o intuito do projeto de substituição de importações. Em 2017, a Rússia forneceu ajuda alimentar à Venezuela para auxiliar o governo de Maduro a estabilizar o país.

2. Bassou $(2016,1)$ chama a atenção para o fato de que, quando recentemente a China propôs a aquisição do grupo agroquímico Syngenta, alguns senadores norte-americanos pediram ao Departamento do Tesouro que estudasse a iniciativa chinesa para detectar "potential consequences for US national security and the American food system”. A Syngenta está entre o grupo das dez maiores sociedades que controlam um terço do mercado mundial de sementes e $80 \%$ do mercado mundial de pesticidas (Ziegler 2013).

3. Para medir o nível de hard power dos Estados, Bassou (2016) considerou o percentual médio da participação de cada país nas seguintes variáveis: população mundial, PIB mundial, financiamento dado à ONU, despesas militares mundiais e superfície mundial.

4. Outra limitação do uso da negação de alimentos como recurso de poder é que o "estrangulamento” poderá levar o Estado a buscar alternativas que diminuam sua vulnerabilidade. No caso russo, embora o estrangulamento ocidental não tenha vindo no setor agrícola, o movimento parece ter catalisado a Doutrina de Segurança Alimentar por demonstrar os riscos de se depender do internacional. Ao invés de buscar ampliar a rede de fornecedores estrangeiros, o Kremlin buscou desenvolver a produção doméstica por meio da agroindustrialização.

5. Paradoxalmente, como apontaremos nas considerações finais, a estratégia calcada na instalação de complexos agroindustriais provavelmente acabará por criar um outro tipo de dependência do mercado internacional: a necessidade de exportar excedentes. 


\section{SEGURANÇA ALIMENTAR RUSSA: ESTRATÉGIA DE AUTONOMIA PARA UMA ESTRUTURA INTERNACIONAL DE INCERTEZAS}

\section{RESUMO}

A insegurança alimentar está atrelada à debilidade do Estado e à instabilidade social. A Rússia contemporânea não parece fugir a esta tendência. Dentre os fatores que podem ter alavancado uma maior preocupação do governo russo em garantir a segurança alimentar estão: as crises dos anos 2000 (sobretudo a alimentar), que expôs a instabilidade do mercado internacional de alimentos; e as sanções impostas pelos governos ocidentais em retaliação às investidas geopolíticas da Rússia no seu entorno. Este artigo - a partir de uma revisão bibliográfica, análise de dados econômicos e exame documental - procurou entender como se dá a estratégia de segurança alimentar da Rússia, intitulada "Doutrina Russa”. Ficou perceptível que a "Doutrina Russa” é uma expressão da busca do Kremlin por redução das vulnerabilidades econômicas do país em um contexto geopolítico que lhe é inóspito, bem como de uma reinserção econômica internacional mais soberana e mais favorável à sua projeção de poder.

Palavras-chave: Segurança alimentar; Doutrina Russa; Geopolítica russa; Poder agroalimentar; Segurança nacional.

\section{ABSTRACT}

Food insecurity is linked to weakness of the State and social instability. Contemporary Russia does not seem to scape this tendency. Among the factors that may have stimulated the preoccupation of the Russian government with ensuring of food security are: the crisis of the 2000s (mainly the food crisis) that exposed the instability of the international food trade; and the sanctions imposed by western governments in retaliation to Russian geopolitics in the region. This article - based on a literature review, analysis of economic data and documentary examination - sought to understand the Russia's food security strategy entitled "Russian Doctrine". It became clear that "Russian Doctrine" is an expression of Kremlin's goal of reducing the economic vulnerabilities in an inhospitable geopolitical context. It is also an initiative to allow a more sovereign participation in the international economy as well as the Russian projection of power.

Keywords: Food Security; Russian Doctrine; Russian Geopolitics; Agrifood Power; National Security.

Recebido em 03/05/2018. Aceito para publicação em 06/12/2018. 